\title{
Looking into the Future
}

\author{
Jens Riis \\ Department of Production, Aalborg University, Denmark
}

E-mail: riis@iprod.auc.dk

Key words: Trends in teaching and industrial needs; Collaborative competencies; New application areas for games; Issues for design and running of simulation games.

\begin{abstract}
Trends in industrial enterprises point to a more dynamic and complex world in which to operate with speed, agility and productivity as key requirements. This will call for increased focus on collaborative skills in handling daily operations as well as carrying out major organisational changes effectively. These industrial needs imply challenges for industrial enterprises to develop new collaborative competencies. But also the teaching of engineering and business students should be changed. The development and use of simulation games for training and social experimentation represents one of several means. However, new types of games and new application areas need to be developed. In light of these challenges the paper discusses selected key issues for the design and running of games.
\end{abstract}

\section{INTRODUCTION}

Games of various kind have successfully been applied in teaching and in industry, in particular to achieve a deeper understanding of the dynamic processes cutting across functions and departments. However, conditions change in industry, and new means become available. As a result, new challenges exist for developing new types of games and for extending areas of application into new fields. 
This chapter has been inspired by a discussion in groups and in a plenary session at the end of the 1998 workshop in Ghent. First, trends in needs and means will be discussed pointing to new challenges for the development and use of games. This leads, in the next section, to a discussion of issues for the design and running of games. Instead of seeking to provide a comprehensive list of trends and means, we have chosen to elaborate on a few issues as representatives of new directions.

\section{TRENDS IN NEEDS AND MEANS}

\subsection{Industrial trends}

\subsubsection{Competence development}

Recent trends in knowledge management and competence development point to a need to focus more attention on collective competencies, instead of only looking at individual knowledge and competencies. The capability of an industrial enterprise to deliver a variety of products on time to customers stems from a complicated interplay of individuals and departments. Although guided by various management systems, many of the actual activities and decision-making processes have an informal nature. Furthermore, very few are able to describe what actually is going on, e.g. when a customer order is handled through engineering design, planning, purchasing, production, assembly and distribution. Thus, key competencies for the competitiveness of a company are informal, owned collectively and not explicitly known (i.e. tacit). This makes it difficult for a company to develop this competence by using traditional courses.

If an analogy is made to the competence of a football team, we may identify different types of competencies. First, each player should be able to receive and deliver the ball, and to run very fast for shorter periods of time during the whole match. Second, the team should be able to handle rather well defined situations, such as a corner and a free kick. Thirdly, what really makes the team win is its capability to spontaneously make use of a specific situation, to establish an attack with many unexpected elements for the other team, etc. It seems apparent that different means should be used for developing competencies of the three types.

As to the last two types, collective practice and collective reflection are important means, e.g. by using video for recording the mutual interplay to stimulate reflection. The notion of agility has become popular in industrial 
enterprises. A football team also needs to be agile, e.g. to adjust the tactics if one of its players becomes hurt, if the other team adopts a new tactics, or if the team is leading the match. Such changes will have to take place spontaneously and need to be immediately understood by all players.

It is our impression that few companies are explicit in their development of collective competencies. But as the competitive situation becomes more dynamic and the product and supply structure more complex, we shall expect that companies increasingly will become aware of the need to develop and apply effective means for developing informal collective knowledge and competence. At present only few means are available, one being the use of simulation games.

Many companies are increasingly addressing extended enterprise issues, e.g. in supply chain management and cross-functional co-operation in new product development. These trends only add to the relevance of developing means for effective collective competence building outlined above.

\subsubsection{Speed and precision in organisational changes}

The dynamic market situation in recent years has pointed to a need for industrial organisations to change with speed and precision, e.g. to design and implement a new production management system, new production pro??cesses, or a new organisational structure. A widely held opinion in industry expects that the time to implement a drastic change is between three to five years, regardless that it may have been planned to last only two years. In order to be successful several issues have to be addressed, such as creation of a common understanding of the need to change, development of a shared vision of future operations, and establishment of a broad comprehension of the complex co-operation implied in the new solution. We believe that games may play an important role in securing industrial enterprises the capability to successfully and speedy implement organisational changes.

\section{$2.2 \quad$ Teaching}

\subsubsection{Stressing new qualifications}

The initiation in the 90's of a large National Science Foundation program on Engineering Education Coalition has been an attempt to change the traditional engineering education in the USA (Coleman 1996). It seeks to change the focus in many engineering schools to stress

- Real-world design 
- Interdisciplinary education

- Teamwork skills

- Integration of materials

Similar initiatives have been seen in Europe seeking to augment the traditional qualifications of engineering graduates. Using a metaphor, it is no longer sufficient to be a qualified spectator to a football match being able to interpret the tactics of the two teams, to explain the individual players' behaviour and to relate the given match to other matches. A graduate should also be able to play football.

In the language of Kolb's learning cycle (Kolb 1984), an engineering graduate should be able to combine all four steps (Abstract conceptualisation i.e. Generalisation; Active experimentation i.e. Testing; Concrete experience; Reflection based on observations). Experience in problem solving and implementation of interdisciplinary issues may, among other things, include

- analysis of a complex problem,

- definition of a project with objectives and scope,

- bringing different specialists' contribution into a holistic solution,

- working together in a group and

- dealing with stakeholders and conflicts of interest

Such qualifications are often neglected. However, many engineering schools have introduced problem oriented teaching methods, such as industrial projects, case studies and simulation games. We are convinced that the quest from industry for more engineering graduates who have been trained in holistic problem solving will continue in the future posing important challenges for engineering education.

\subsubsection{New means}

New means are likely to change the nature of the teaching of engineering and business students. With respect to subjects that are dominated by factual knowledge new means, such as internet, multi-media, etc. offer stimulating opportunities for self-studying and group mode computer supported learning processes. These new simulation based, computer assisted learning methods have almost unlimited possibilities. They can be built into normal courses as assignments, integrated into modules in case based teaching, as well as used in a 'stand-alone' mode for experimental learning. And they can be used in university teaching as well as in company training.

The hypertext mode of organising knowledge and experiences allows for easy switch between theory, practical examples, methods, etc. This suggests a new problem oriented mode of self-studying that holds potential for appealing to many students. From a predominantly teacher dominated learning process with lectures on theories given at times when the teacher 
finds it relevant, the hyptertext structure allows students to study theory when they have a question and to look at several practical examples illustrating how theory may be used when they seek solutions to a specific problem.

There is a marked need for a different driver of the learning process than the teacher's lectures and planned exercises. Case studies have been used to serve as such a driver, as have also student projects. The use of games and social simulation also serve as a vehicle for this type of learning. This will however require that the game be more strongly integrated with the learning processes, to include dealing with theoretical questions that stimulate discussion and interpretation. Also the players' analyses and proposed solutions may be fed into the memory of the game and offered to players in the following runs of the game, (cf. Riis et al. 1998).

As a first attempt to offer information about different games, a catalogue of games has been established on the internet http://iprod.auc.dk/xproj/gamespm/www-games.html

\section{ISSUES IN DESIGN AND OPERATION OF GAMES}

We have selected two major issues implicitly suggested in the preceding section; one dealing with post game behaviour in an effort to maximise the benefit from the game; and one pointing to a new application area for games, namely for extracting knowledge and experiences from ill-defined tasks.

\subsection{Post game behaviour}

In the past, for good reasons much focus has been placed on the game itself, including its design, test and operation. However, several issues will be increasingly important in the future related to post game behaviour.

\subsubsection{Transferability}

Often the setting of the game is different from that of the company; or in the case of teaching student the setting is not directly related to a specific method or theory. The transfer of observations, impressions and experiences from playing the game is an issue that will be as important as it has always been. 


\subsubsection{Making use of the experience of facilitators}

Experience indicates that the facilitator plays a key role in the successful application of games. As games become a more integral part of teaching and organisational changes processes, as pointed out in the preceding section, the role of the facilitator will include more behavioural elements in addition to knowledge of the subject matter, e.g. production planning.

The facilitator's experience gathered through several games represents valuable knowledge for new facilitators. It is a challenge to ask the facilitator to extract the experiences gained and convey them to others. For instance, the instructor's manual may be continuously updated to include "good advices" and potential roadblocks to pay attention to. There is a need for a more systematic reflection on facilitators' often tacit experiences. To the extent possible, the tacit knowledge of facilitators should be externalized and incorporated into the contents of the game itself.

\subsubsection{Games as an integral part of the learning process}

As pointed out in the preceding section, using games in hypertext modes of teaching requires a re-thinking of the way in which games are carried out. From a more or less stand-alone educational activity, the game processes will be combined with exercises and reading of relevant literature.

\subsubsection{Organizational change processes take time}

When games are used for training specified skills, it may be relatively easy to measure the effect of the game. But increasingly games of various kinds are employed in the early phases of an organisational change process to create a commonly shared perception of the current mode of operation and a need to change (cf Smeds and Haho 1995, Haho and Smeds 1997). As a consequence, the effect of the game may be a change in attitude and a better understanding of the mutual interaction of activities in the departments involved. In such cases it is difficult to distinguish the effect of the game from parallel and serial activities.

If however it is decided to measure the effect of a game, the changes in attitude and willingness to change are as important to measure as the actual increased knowledge and changed behaviour. Also the change management itself can be measured, and the effects of the simulation game on the success of the change project can be assessed. 


\subsection{Making tacit knowledge explicit}

As pointed out in a preceding section, industrial enterprises need to address how to identify and strengthen tacit knowledge and competencies held by a group of individuals around performing a complex task, e.g. handling customer orders. Provoked by the focused discussion in the late 80's of designing expert systems by means of a knowledge engineer who would attempt to codify the experience of experts, we have suggested a different approach (Merit \& Riis 1988). Experts should be invited to play a game that would address situations similar to their own. This would allow their experience to be made explicit in a holistic setting in which different objectives are at play and different perspectives are employed. Different opinions and experiences may not be in conflict, because they relate to different objectives and perspectives.

During a game, attention would be drawn to essential issues and experiences. Furthermore, a game will offer an opportunity for mutual learning by which experts are asked to reflect on their experience and compare it with others. The use of a game represents a laboratory setting with some controllable variables. This will permit the use of the game with another group of experts to test the robustness of opinions, practice, and explicit knowledge of phenomena.

In view of it complex nature we need to adopt an experimental approach in seeking new ways of making tacit, collective knowledge and experience more explicit. Games hold potential for contributing to this endeavour, even in view of the difficulties and limitations of using games for this purpose. It will represent a new way of using games.

\section{CONCLUSION}

In view of the more dynamic and complex world in which industrial enterprises will operate with speed, agility and productivity as key requirements, we have identified new challenges. It was argued that key competencies for the competitiveness of a company in nature are informal, owned collectively and not explicitly known. Thus, there is a need for developing means for strengthening collaborative competencies. Also the speed and precision with which organisational changes are executed need to be increased. In particular it was pointed out that we need better means for creating a commonly shared perception of the need to change and a shared vision of future operations.

With respect to teaching engineering and business students an shift of focus was identified to also include problem solving skills. Using a meta- 
phor, it is no longer sufficient to become a qualified spectator of a football match; a graduate should also be able to play football.

New means may change the role of games in teaching. It was argued that the application of hyptertext mode of organising knowledge and experiences would call for a driver of the learning process. The proven success of games led to suggest games as one of such drivers.

New ways of using games point to increased emphasis on post game behaviour, e.g. to let a game be a more integral part of learning and organisational processes. Finally, it was argued that games may be instrumental in making informal, collective knowledge and experience more explicit.

\section{REFERENCES}

Coleman, Robert J. (1996) The Engineering Education Coalition, ASEE PRISM, Sept

Haho, P. and Smeds, R (1997). The Softmatch-method: Enterprise Transformation through Simulation Games. P. 48-63 in Peter Saunders and Benita Cox (Eds.): The Simulation and Gaming Yearbook Volume 5: Research into Simulations in Education. Kogan Page, London

Kolb, David A. (1984) Experiential learning. Prentice-Hall, New Jersey

Merit, Søren \& Jens O. Riis (1988) Knowledge Acquisition by Means of Games, Proceedings of the IFIP WG 5.7 Working Conference on Knowledge Based Production Management Systems, Chapman \& Hall

Riis, Jens O., Uffe Thorsteinsson, Ari Barfod \& Erik Lyngsie (1998) The role of games in a model company, p. 77 - 86 in Experimental Learning in Production Management edited by Riitta Smeds and Jens O. Riis, Chapman \& Hall

Smeds, R. and Haho, P. (1995) Tailored order-to-delivery process game. P. 145-155 in-+ Jens Riis (ed): Simulation Games and Learning in Production Management, Chapman \& Hall, London

\section{BIOGRAPHY}

\section{Jens Riis}

Jens O. Riis is Professor of Industrial Management Systems at the Department of Production, Aalborg University. His research areas include industrial management, technology management and project management. 